\title{
Quality of Bedside Procedures Performed on General Medical In-patients: Can We Do Better?
}

\author{
Thomas E. MacMillan MD, Robert C. Wu MD MSc, Dante Morra MD MBA
}

\begin{abstract}
About the Authors
Thomas MacMillan (right) is a clinical assistant in the Department of Medicine at University Health Network, in Toronto, Ontario. His research interests include patient safety and quality improvement, in-patient procedures, and medical education. Robert Wu is a member of the Department of Medicine, University of Toronto, and the Centre for Innovation in Complex Care, University Health Network, in Toronto. Dante Morra is a member of the Department of Medicine, University of Toronto, and Trillium Health Partners, in Mississauga, Ontario. Correspondence may be directed to t.macmillan@mail.utoronto.ca.
\end{abstract}

\section{Summary}

Little is known about the quality of procedures performed on general internal medicine inpatients. Many general medical in-patients require diagnostic or therapeutic procedures, such as thoracentesis, paracentesis, joint aspiration, and lumbar puncture. While some data exist regarding the safety of specific procedures, little is known about other important measures of quality, such as success rate, adequacy of the diagnostic specimens obtained, wait time, accuracy and completeness of clinical documentation, and patient satisfaction. Although increasing numbers of procedures are being performed by interventional radiologists, the impacts of this shift have not been well studied.

During the course of a 2-week quality improvement audit, the authors observed a high frequency of unsuccessful bedside procedures, instances of inappropriate diagnostic testing, inadequate documentation, and lapses in communication. This should be a call to action for general internists to better characterize the quality of in-patient procedures.

\section{Résumé}

Nous n'en savons pas beaucoup sur la qualité des interventions, qui relèvent de la médecine interne générale, subies par les malades hospitalisés. Des interventions diagnostiques ou thérapeutiques sont effectuées dans bon nombre de cas aux unités de médecine générale, qu'il s'agisse de thoracentèse, de paracentèse, de ponction articulaire ou lombaire. Nous disposons de données sur la sécurité de certaines interventions, mais nous en savons très peu sur d'autres aspects importants de la qualité de l'intervention, notamment le taux de réussite, le caractère approprié du prélèvement en vue de poser le diagnostic, le temps d'attente, la précision et l'exhaustivité de la documentation clinique et la satisfaction du patient. Par ailleurs, les radiologistes interventionnels exécutent de plus en plus d'interventions, sans que l'on ait étudié en profondeur l'effet de ce changement dans la pratique.

Au cours d'une vérification de l'amélioration de la qualité qui a duré deux semaines, les auteurs ont observé un taux élevé d'interventions vaines au chevet de patients, de choix d'épreuves diagnostiques inappropriées, de documentation insuffisante et de problèmes de communication. Ces constatations devraient inciter les internistes généralistes à mieux définir la qualité des interventions effectuées auprès des malades hospitalisés. 
$\mathrm{W}$ hile invasive diagnostic and therapeutic procedures are frequently performed on general internal medicine (GIM) in-patients, little is known about the quality of these procedures. GIM in-patients often require bedside procedures such as thoracentesis, paracentesis, joint aspiration, lumbar puncture, and bone marrow biopsy, although the exact frequency of these procedures has not been well characterized in the literature. Invasive procedures are a potential source of harm to patients if errors occur during their performance. Surprisingly, there is a paucity of data on the quality of bedside procedures performed in hospitals.

Previous studies on procedural quality have generally focused solely on complication rates, neglecting other important aspects of quality. ${ }^{1,2}$ Although minimizing complications is an essential component of procedural quality, other important aspects include the number of attempts, rate of success, waiting time, length of stay in hospital, appropriateness of diagnostic samples obtained, accuracy and completeness of procedural documentation, error rate, and patient satisfaction. One study of lumbar punctures found that documentation of opening pressure was poor and that clinicians frequently failed to order a serum glucose. ${ }^{3}$ Whether these findings are generalizable to other procedures or clinical settings is not known.

Increasing numbers of procedures are being performed by interventional radiologists using imaging guidance. ${ }^{4}$ The implications of this shift from the bedside to the radiology department have not been well studied, particularly with regard to procedural quality. There are a number of possible explanations for this trend, such as lack of clinician comfort with performing the procedure, inadequate supplies, insufficient time, or patient factors such as body habitus or characteristics of the fluid collection such as loculation. There is good evidence that GIM clinicians are performing fewer bedside procedures and are less confident in their bedside procedural skills. ${ }^{5}$

A number of recent experiences at our academic tertiary care centre prompted us to examine the issue of procedural quality. We have observed instances of long wait times for interventional procedures, including a patient who waited 88 hours in hospital for a thoracentesis. We have frequently observed cases where an inappropriate set of diagnostic samples was ordered, such as neglecting to order a fluid $\mathrm{pH}$ in cases of suspected complicated pleural effusion. We have observed numerous instances of incomplete documentation including cases where it was not possible to determine which side a thoracentesis had been performed on. Finally, several of our patients had experienced wrong-side thoracentesis, both at the bedside and by interventional radiology, which is considered "never event."

\section{Audit of Procedural Quality}

These experiences prompted us to perform a small quality improvement audit. A secondary goal of the audit was to develop methods to assess and measure procedural quality. We conducted the audit over a 2-week period in January 2012 on GIM at Toronto General Hospital. The procedures examined were thoracentesis, paracentesis, lumbar puncture, and arthrocentesis. Eligible procedures were identified by contacting the clinicians on a daily basis and reviewing the sign-over list and list of pending procedures on a "digital whiteboard" application. Relevant data were abstracted from the chart. Where necessary, additional data were gathered from the clinicians who performed the procedures. During this time, 19 procedures were attempted, of which 14 were at the bedside and 5 were performed by interventional radiology. There were 4 thoracenteses, 6 paracenteses, 8 lumbar punctures, and 1 arthrocentesis.

Of bedside procedures performed, only 7 (50\%) were successful. The most common reason for failure was inability to aspirate fluid. Less than one quarter of bedside procedures were performed using ultrasound guidance. Of the 14 procedures, 1 was performed by a medical student, 8 by a 1st-year resident, 3 by a 2 nd-year resident, 3 by a 3rd-year resident, and 2 by a consulting clinician for which the level of training was not recorded. Seven $(50 \%)$ of the procedures were documented as supervised. We also observed that none of our operators used procedural timeouts or checklists, even though these techniques have been shown to improve outcomes in related areas such as surgical procedures. ${ }^{6}$

Over half of the bedside procedures were performed on evenings or weekends. During the daytime, 3 of $5(60 \%)$ of procedures were successful, compared with 4 of 9 (44\%) of procedures at night or on the weekend, suggesting that procedures were more likely to be successful during the daytime. Possible reasons for this are that during the daytime there is a lower workload and more time for trainees to devote to procedures, as well as the increased availability of support and supervision by more senior trainees or staff physicians.

The quality of documentation was often suboptimal. For example, less than half of the procedures we audited documented the specific risks of the procedure that were explained to the patient, the amount of local anaesthetic, or the side the procedure was performed on (i.e., left or right). The hospital discharge summary included the date of the procedure in only $66 \%$ of cases and the results of the procedure in $75 \%$ of cases.

There was significant variability in the quality of the analysis for diagnostic procedures. For example, only 1 of 3 diagnostic 
paracenteses included both an ascitic fluid albumin and a serum albumin, which are essential for calculating the serum-ascites albumin gradient, a test to rule out portal hypertension as the cause of ascites. ${ }^{7}$ We observed some instances of waste where diagnostic tests were ordered that are not known to be helpful (e.g., osmolality and phosphate were ordered on pleural fluid).

Finally, we observed frequent lapses in communication when clinicians ordered an interventional radiology procedure. The ordering clinicians often failed to specify important details such as the indication for the procedure (e.g., therapeutic or diagnostic), the desired amount of fluid to be removed for therapeutic procedures, or the desired diagnostic samples to be collected. There was no standard method of communicating with the interventional radiology department, and in many cases minimal or no communication occurred.

\section{A Call to Action to Improve Procedural Quality}

This audit and our anecdotal experiences have convinced us of the pressing need to study the quality of in-patient procedures. A number of questions are raised by these findings. In an era with considerable pressure to reduce patient length of stay, is a delay of over 3 days for a procedure acceptable? What can be done to improve the success rate of bedside procedures? What methods are being used to teach and assess residents' procedural skills? What systems are in place to monitor the quality of procedures? How often is an appropriate set of diagnostic specimens obtained, and how frequently are repeat procedures required?

We believe that similar conditions to ours exist at other centres, making further study imperative to delineate the extent of the problem. An essential first step is to develop robust mechanisms to track procedural quality. There is an urgent need for quality improvement interventions in this area, which will likely impact on multiple domains, including education and training, procedures and policies, equipment and supplies, health information technology, and communication.

Medical education is one area of potential improvement that deserves special mention. In many academic teaching centres, much of the teaching and training in procedural skills to residents is non-standardized, with few systematic methods for assessing competency. ${ }^{8}$ There are a number of promising advances in the area of procedural education, such as dedicated procedure services and simulation. ${ }^{9,10}$ Whether these interventions will improve procedural quality in practice remains to be demonstrated.

The ideal use of bedside sonography for procedures also warrants examination. The use of sonography is now standard for central venous catheterization, and its application in other procedures is evolving. The British Thoracic Society strongly

\begin{tabular}{|c|c|}
\hline Measure & Submeasures \\
\hline \multicolumn{2}{|l|}{ Informed consent obtained } \\
\hline \multicolumn{2}{|l|}{ Waiting time } \\
\hline \multicolumn{2}{|l|}{ Use of procedural timeout } \\
\hline \multicolumn{2}{|l|}{ Use of sonography } \\
\hline \multicolumn{2}{|l|}{ Number of attempts } \\
\hline \multicolumn{2}{|l|}{ Success rate } \\
\hline \multicolumn{2}{|l|}{ Complication rate } \\
\hline Diagnostic sampling quality & $\begin{array}{l}\text { Completeness of diagnostic tests } \\
\text { Avoidance of waste }\end{array}$ \\
\hline Documentation quality & $\begin{array}{l}\text { Completeness } \\
\text { Legibility (for handwritten notes) } \\
\text { Accuracy }\end{array}$ \\
\hline Errors & $\begin{array}{l}\text { Wrong side } \\
\text { Need for repeat procedure }\end{array}$ \\
\hline
\end{tabular}

Patient satisfaction

recommends the use of sonography for all procedures to obtain pleural fluid. ${ }^{11}$ Bedside sonography has been explored for use with paracentesis, ${ }^{12}$ arthrocentesis, ${ }^{13}$ and lumbar puncture. ${ }^{14}$ It is not difficult to envision a future where portable sonography will be as indispensable to a clinician as a stethoscope. We believe that it is imperative for internists to develop competency in bedside sonography and to maintain their bedside procedural skills.

Sonography use may also improve the success rate of bedside procedures. In one study comparing sonography and clinical examination for localizing pleural fluid, sonography use improved the rate of accurate site selection by $26 \% .{ }^{15}$ Another study of sonography use in paracentesis performed by emergency department physicians found that sonography use improved the success rate to $95 \%$, compared with $61 \%$ for traditional paracentesis. ${ }^{12} \mathrm{~A}$ recent survey of internal medicine program directors found that $25 \%$ have implemented a formal curriculum for sonography use in bedside procedures, suggesting that sonography use will become increasingly common in academic teaching hospitals. ${ }^{16}$

\section{Proposed Measures for Assessing Procedural Quality}

We propose a number of practical measures that can be used to evaluate procedural quality in a more comprehensive way, rather than focusing solely on complication rates (Table 1). The use of these measures is encouraged in future studies on procedural quality.

\section{Conclusions}

We have observed deficiencies in the quality of procedures performed on internal medicine in-patients at an academic tertiary-care hospital. Similar conditions likely exist at other 
health care facilities. There has been little research on this area to date, and further study is required to better characterize the quality of procedures on GIM in-patients. We have proposed a list of measures that can be used to assess the quality of diagnostic and therapeutic procedures in future studies.

\section{Acknowledgements}

We thank the following individuals for helpful comments on earlier drafts of this article: Brian Wong, Ryan Bridges, and Lynfa Stroud.

This work was part of a poster presentation at Higgins Day, Annual Research Day, St. Michael's Hospital, in Toronto, Ontario, May 17, 2012.

\section{References}

1. Daniels CE, Ryu JH. Improving the safety of thoracentesis. Curr Opin Pulm Med 2011;17(4):232-6.

2. Duncan DR, Morgenthaler TI, Ryu JH, Daniels CE. Reducing iatrogenic risk in thoracentesis: establishing best practice via experiential training in a zerorisk environment. Chest 2009;135(5):1315-20.

3. Hewett R, Counsell C. Documentation of cerebrospinal fluid opening pressure and other important aspects of lumbar puncture in acute headache. Int J Clin Pract 2010;64(7):930-5.

4. Wigton RS, Alguire P. The declining number and variety of procedures done by general internists: a resurvey of members of the American College of Physicians. Ann Intern Med 2007;146(5):355.

5. Wickstrom GC, Kolar MM, Keyserling TC, et al. Confidence of graduating internal medicine residents to perform ambulatory procedures. J Gen Intern Med 2000;15(6):361-5.
6. Schlack WS, Boermeester MA. Patient safety during anaesthesia: incorporation of the WHO safe surgery guidelines into clinical practice. Curr Opin Anaesthesiol 2010;23(6):754-8.

7. Wong CL, Holroyd-Leduc J, Thorpe KE, Straus SE. Does this patient have bacterial peritonitis or portal hypertension? How do I perform a paracentesis and analyze the results? JAMA 2008;299(10):1166-78.

8. Huang GC, Smith CC, Gordon CE, et al. Beyond the comfort zone: residents assess their comfort performing inpatient medical procedures. Am J Med 2006;119(1):71.e17-24.

9. Lucas BP, Asbury JK, Wang Y, et al. Impact of a bedside procedure service on general medicine inpatients: a firm-based trial. J Hosp Med 2007;2(3):143-9.

10. Millington SJ, Wong RY, Kassen BO, et al. Improving internal medicine residents' performance, knowledge, and confidence in central venous catheterization using simulators. J Hosp Med 2009;4(7):410-6.

11. Havelock T, Teoh R, Laws D, Gleeson F, on behalf of the BTS Pleural Disease Guideline Group. Pleural procedures and thoracic ultrasound: British Thoracic Society pleural disease guideline 2010. Thorax 2010;65 Suppl 2:i61-76.

12. Nazeer SR, Dewbre H, Miller AH. Ultrasound-assisted paracentesis performed by emergency physicians vs the traditional technique: a prospective, randomized study. Am J Emerg Med 2005;23(3):363-7.

13. Wiler JL, Costantino TG, Filippone L, Satz W. Comparison of ultrasoundguided and standard landmark techniques for knee arthrocentesis. J Emerg Med 2010;39(1):76-82.

14. Ferre RM, Sweeney TW, Strout TD. Ultrasound identification of landmarks preceding lumbar puncture: a pilot study. Emerg Med J 2009;26(4):276-7.

15. Diacon $\mathrm{AH}$, Brutsche $\mathrm{MH}$, Solèr $\mathrm{M}$. Accuracy of pleural puncture sites: a prospective comparison of clinical examination with ultrasound. Chest 2003;123(2):436-41.

16. Schnobrich DJ, Gladding S, Olson APJ, Duran-Nelson A. point-of-care ultrasound in internal medicine: a national survey of educational leadership. J Grad Med Ed 2013;5(3):498-502.

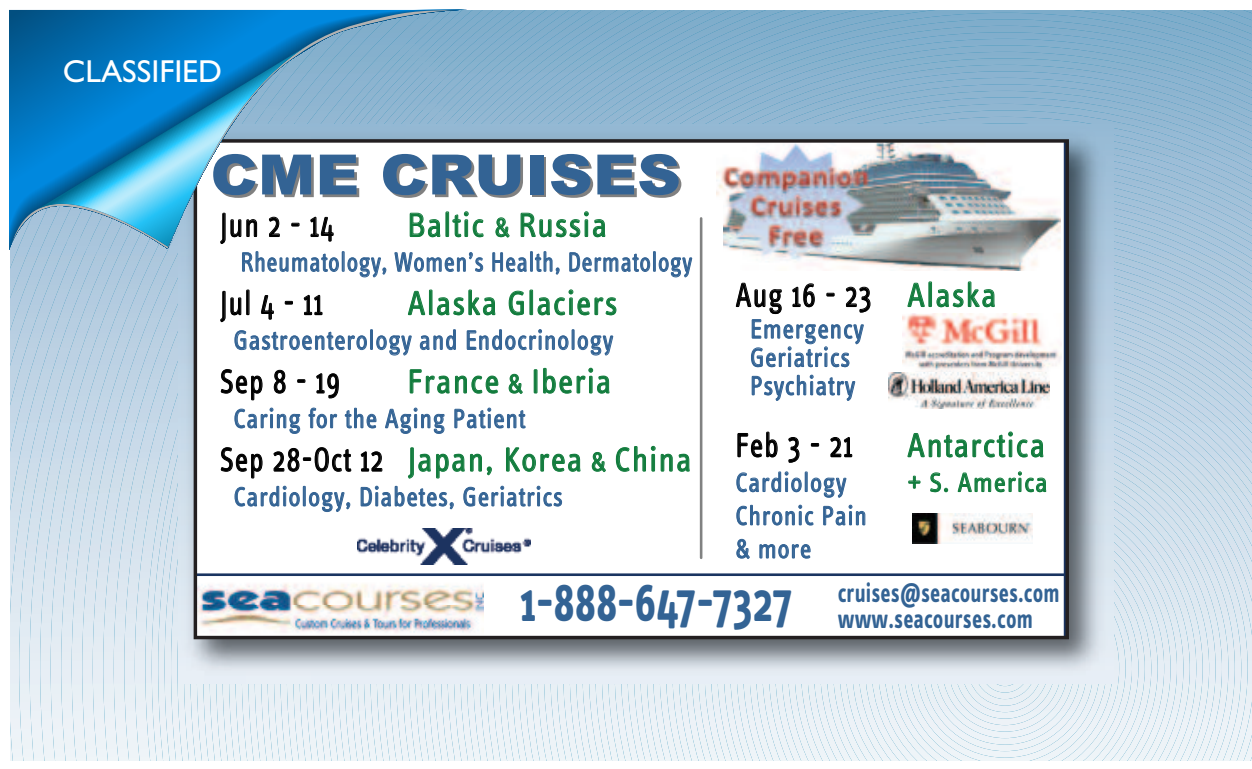

